\title{
A PROPOSAL FOR THE ESTABLISHMENT OF TWO NEW HAEMOPHILUS SPECIES
}

\author{
E. L. Biberstein * AND D. C. White \\ Moredun Research Institute, Edinburgh, Scotland, and School of Medicine, \\ University of Kentucky, Lexington, Kentucky, 40506, USA
}

THE need for certain cofactors for growth constitutes the main criterion for the inclusion of a Gram-negative bacterium in the genus Haemophilus, and the nature of these requirements determines the assignment of organisms to species within the genus. The characterisation of the species in regard to their cofactor requirements is therefore an important consideration for any future work of a determinative nature.

Like the type species $H$. influenzae, the organism known at present as Haemophilus suis was originally described (Lewis and Shope, 1931) as requiring two accessory factors for growth: $\mathrm{X}$, which is supplied by haem or certain other porphyrins, and $\mathrm{V}$, which has to be furnished as niacinamide adenine dinucleotide (NAD, DPN) or its riboside precursor. More recently it has been observed that the overwhelming majority of cultures obtained from the respiratory tract and inflamed serous membranes of swine and agreeing in other characters with $H$. suis did not require the $\mathrm{X}$ factor for growth, were capable of forming haem enzymes in the absence of preformed iron porphyrins, and could synthesise porphyrin from delta-aminolaevulinic acid (ALA), an accomplishment thus far never observed with X-requiring cultures of Haemophilus (Biberstein, Mini and Gills, 1963; White and Granick, 1963). Of ten porcine isolates resembling $H$. suis, nine were unaffected in their growth by additions of $\mathrm{X}$ factor. The same nine readily converted ALA to porphyrin. The one remaining culture failed to do so and required preformed haem for growth, thus corresponding to the description of Lewis and Shope. The existence of two biotypes of porcine, non-haemolytic haemophili is therefore beyond question.

A somewhat analogous situation evidently exists in regard to Haemophilus gallinarum. De Blieck (1934), who first isolated the "haemoglobinophilic" bacterium from fowl coryza, flatly stated that it required the $X$ factor. The experimental procedure that led him to this conclusion is not revealed, however. McGaughey (1932), who studied eleven poultry isolates from coryza outbreaks and other sources including healthy birds, could discover no benefit from adding $\mathrm{X}$ factor to his propagating medium. The $\mathrm{X}$ factor employed by him was a solution of commercially obtained haemin, and yeast extract supplied

Received 18 Oct. 1968; accepted 30 Oct. 1968.

* Permanent address: School of Veterinary Medicine, University of California, Davis, California, 95616, USA.

J. MED. MICROBIOL.-VOL. 2 (1969) 
the $\mathrm{V}$ factor. The strains he investigated were of two distinct cultural types, one of which very likely was not the fowl coryza bacterium (see below).

The need for X factor was convincingly demonstrated by Schalm and Beach (1936), who showed that eight fowl coryza cultures obtained in various parts of the United States required two kinds of supplement, one heat-stable and the other heat-labile. In the crucial experiment the strains grew satisfactorily in broth containing 10 per cent. fresh horse serum and 10 per cent. autoclaved horse blood extract, but not in broth lacking either or both of these ingredients. Similar conclusions regarding such dual requirement were reached by Delaplane, Erwin and Stuart (1938) who used the same source of $\mathrm{X}$ factor and yeast extract as V-factor supplement.

A subsequent study by Gregory (1944) of five cultures of $H$. gallinarum, including one used by Delaplane et al., and two control strains of $H$. influenzae, failed to shed any light on the $\mathrm{X}$-factor requirement of the former because both the $H$. influenzae cultures, whose $\mathrm{X}$ factor need is undisputed, could be serially propagated in his medium containing only V-factor supplement (yeast extract). It is noteworthy that this piece of work, the limitations of which its author recognised and stressed, is quoted in some texts (Soltys, 1963; Merchant and Packer, 1967) as documentation of the X-factor-independence of $H$. gallinarum. Definitive evidence of the existence of X-independent fowl coryza organisms was presented by Page (1962), who used reduced NAD as V factor and haemin as X factor. All his eight cultures grew "repeatedly" in the absence of haemin and derived no apparent benefit from its presence. His conclusions were supported by the observations of Biberstein et al., who found that four of the same eight strains were able to synthesise porphyrin from ALA. A second pertinent aspect of Page's investigation is his description of haemophilic organisms in the avian respiratory tract other than the fowl coryza bacterium. These organisms differed from the latter in their cultural and serological properties, and in their inability to cause respiratory disease, although they could be recovered during coryza outbreaks alongside the true aetiological agent. They were far less exacting in their nutritional and atmospheric requirements than the pathogenic strains, and we found them indistinguishable by any major criterion from $H$. parainfluenzae. That they have previously been observed in other parts of the world is very strongly suggested by McGaughey's description of his " $H$ " strains, which made up 5 of his 11 cultures. How often such easily cultivable, X-independent and frequently somewhat pigmented strains were involved in other early investigations can only be surmised from a careful reading of descriptive features, particularly those pertaining to pathogenicity and atmospheric needs. Accounts omitting such descriptions must be discounted heavily on that basis alone, and any statement they contain regarding X-factor requirement loses all relevance to the present discussion.

The situation concerning $\mathrm{X}$ factor in $H$. gallinarum thus stands as follows. The cultures studied by Schalm and Beach, and readily recognisable as $H$. gallinarum by their atmospheric peculiarities, required both $\mathrm{X}$ and $\mathrm{V}$ factors. Page concluded from his own observations that avian strains of Haemophilus 
do not require haemin (or $\mathrm{X}$ factor) for growth, implying that previous reports of such requirements were incorrect. Unfortunately there does not appear to be at present any way of testing this contention as the cultures of Schalm and Beach are not available for re-examination. A careful reading of their report reveals nothing that would account for their observations in any other way than they did. Since their conclusions were also in agreement with previous descriptions of the organism by its discoverer (De Blieck) and were confirmed independently shortly thereafter (Delaplane et al.) their validity is difficult to challenge now, and $H$. gallinarum is accordingly described as X-requiring in standard taxonomic works and textbooks (Pittman, 1957; Wilson and Miles, 1964). The evidence now before us compels us to acknowledge the existence of an additional, X-independent but otherwise indistinguishable form. Thus, a revision of the nomenclature is required for both the porcine and avian haemophili.

It is the accepted convention in the naming of Haemophilus species to use the prefix "para-" for organisms that lack the $X$ requirement shown by existing, otherwise similar species. The species $H$. parainfluenzae, $H$. parahaemolyticus, and, most recently $H$. paraphrophilus (Zinnemann et al., 1968) illustrate this usage. We therefore propose the establishment of two new species, Haemophilus parasuis and Haemophilus paragallinarum, to comprise cultures that resemble $H$. suis and $H$. gallinarum, respectively, in all regards except in their lack of requirement for X-factor supplementation.

\section{SUMMARY}

There is good evidence for the existence of two groups of bacteria that differ from Haemophilus suis and $H$. gallinarum only in not requiring the supply of $\mathrm{X}$ factor for growth. It is proposed that these groups should be established as new species named, respectively, Haemophilus parasuis and $H$. paragallinarum.

\section{REFERENCES}

Biberstein, E. L., Mini, Patricia D., ANd 1963. J. Bact., 86, 814.

Gills, MarJorie G.

DE BLIECK, L.

1934. XII Int. Vet. Congr., N.Y., 1, 161.

Delaplane, J. P., Erwin, L. E., and 1938. J. Agric. Res., 56, 919.

STUART, H. O.

Gregory, D. W. . . . . . . . 1944. Amer. J. Vet. Res., 5, 72.

Lewis, P. A., AND Shope, R. E. . . . 1931. J. Exp. Med., 54, 361.

MCGaughey, C. A. . . . . . . . 1932. J. Comp. Path., 45, 58.

Merchant, I. A., AND PACKer, R. A. - 1967. Veterinary bacteriology and virology,

PAGE, L. A. 7th ed., Ames, Iowa, p. 358.

1962. Amer. J. Vet. Res., 23, 85.

Pittman, Margaret . . . . . . 1957. In Bergey's Manual of determinative bacteriology, 7th ed., edited by R. S. Breed, E. G. D. Murray and N. R. Smith, Baltimore, p. 407. 
Schalm, O. W., AND BeACH, J. R. . . 1936. J. Bact., 31, 161.

SoltYS, M. A. . . . . . . . . 1963. Bacteria and fungi pathogenic to man and animals, London, p. 394.

White, D. C., AND Granick, S. . . 1963. J. Bact., 85, 842.

Wilson, G. S., AND Miles, A. A. . . 1964. Topley and Wilson's Principles of bacteriology and immunity, 5th ed., London, p. 962.

Zinnemann, K., Rogers, K. B., Frazer, 1968. J. Path. Bact., 96, 413. JOYCE, AND BOYCE, J. M. H. 